\title{
Invited review: Milk phospholipid vesicles, their colloidal properties, and potential as delivery vehicles for bioactive molecules
}

\author{
E. Arranz $z^{*}$ and M. Corredig* $\dagger^{1}$ \\ *Department of Food Science, University of Guelph, Guelph, ON, N1G 2W1, Canada \\ †Gay Lea Foods, Research and Development, Speedvale Avenue W, Guelph, ON, N1H 1J5, Canada
}

\begin{abstract}
The milk fat globule membrane (MFGM) is a unique colloidal assembly of phospholipids and proteins, with numerous potential applications as functional ingredient. The phospholipid components of the MFGM are gaining interest as they are a useful matrix for use as a constituent of delivery systems such as liposomes. Liposomes formulated with milk phospholipids are becoming an alternative to other sources of phospholipids such as soybean or egg yolk. However, incorporation of phospholipids fractionated from the milk fat globule membrane in dairy products requires an in-depth understanding of the functional properties of phospholipids. In particular, it is critical to understand which factors play a role in their stability and bioefficacy as delivery systems. Moreover, chemical and physical modifications of phospholipid liposomes occurring during digestion and the fate of the encapsulated compounds are very important to understand. This review discusses recent findings on the structure and functionality of MFGM, the bioactivity of the phospholipids fraction, their utilization as delivery systems, and their stability through gastrointestinal transit.
\end{abstract}

Key words: milk fat globule membrane, polar lipid, liposome, bioactivity, gastrointestinal tract

\section{INTRODUCTION}

Consumer demand for foods with benefits beyond nutrition is continuously growing and has led to an increase in research into design of food matrices that can deliver biological functionality with consumption. In this context, several studies have been conducted to better evaluate the potential use of minor components in milk as functional ingredients.

Milk is an aqueous solution that contains mainly fat, proteins, lactose, and minerals; it is an exceptional

Received October 31, 2016.

Accepted December 7, 2016.

${ }^{1}$ Corresponding author: mcorredi@uoguelph.ca source of energy for breast-fed infants, providing essential nutrients and bioactive compounds. Milk contains about 3 to $5 \%$ fat, which exists in milk fat globules (Jensen, 2002). The stability of this oil-in-water emulsion is maintained by a thin lipid layer, the milk fat globule membrane (MFGM), that surrounds the fat globules, preventing them from coalescing freely. Milk fat globules are unique colloidal structures $(0.1-20 \mu \mathrm{m}$ in diameter), naturally and exclusively found in milk. The MFGM results from the secretion of milk fat globules from epithelial cells of the mammary gland, and its structure has been extensively studied (see, for example, Lopez, 2011). A proteomics study of MFGM revealed that the composition of bovine MFGM includes 69 to $73 \%$ lipid and 22 to $24 \%$ protein. The protein accounts only for 1 to $4 \%$ of total milk protein but includes several proteins exclusive to the MFGM with recognized biological functionality (Cavaletto et al., 2008).

The milk fat globules have a polydisperse size distribution, and this polydispersity is conserved among species and may be of biological significance (Michalski et al., 2005a). The smaller the size of the globule, the greater the surface area available for interactions with other molecules or microorganisms in the gut. An indepth study of milk fat globules in human milk demonstrated that, in addition to large milk fat globules, there is a large population of nanodroplets, with an average diameter of $25 \mathrm{~nm}$, composed of proteins and lipids, called lactosomes (Argov et al., 2008). In contrast to the large milk fat globules, lactosomes do not contain a substantial triglyceride core and are not a source of energy for the neonate. Rather, it is thought that their surface components have important biological functionality; for example, immunomodulatory functions (Argov-Argaman et al., 2010). These particles have a similar density to plasma high-density lipoproteins, and can be separated from other milk fat globules by ultracentrifugation. Lipidomic and proteomic analyses on these natural nanostructures suggest that they derive from a different secretory or biosynthetic pathway than milk fat globules (Argov-Argaman et al., 2010).

Fragments of MFGM can be found in dairy products, with buttermilk and butter serum (the byproducts from 
the churning of cream for butter making) containing the highest concentrations (Dewettinck et al., 2008; Vanderghem et al., 2010). During butter making, the milk fat globules are destabilized and disrupted, causing the release and agglomeration of milk fat and the selective concentration of the MFGM fractions and most of the water-soluble material into the aqueous phase, known as sweet buttermilk. This fraction also contains a substantial amount of protein derived from skim milk, and sodium citrate can be used to dissociate the caseins and allow for fractionation of MFGM material from buttermilk (Corredig et al., 2003). Other alternatives for the extraction of the MFGM from buttermilk include the use of ultrafiltration followed by supercritical fluid extraction to obtain an ingredient especially enriched in phospholipids (Costa et al., 2010).

The MFGM act as natural emulsifiers in milk. The fraction isolated from buttermilk can be utilized as a functional ingredient to stabilize oil-in-water emulsions. The functional properties of such isolates depend on their processing history (Corredig and Dalgleish, 1998). The phospholipid fractions are of particular interest because they have shown to have biological functionality in addition to their processing functionality (Snow et al., 2010, 2011; Zanabria et al., 2014a,b). Recently, milk phospholipids isolated from MFGM fractions became commercially available and new possibilities have opened based on the ability of phospholipid liposomes to entrap bioactive compounds. Numerous publications have focused on the characterization of liposomes obtained using phospholipids derived from the MFGM (see, for example, Thompson et al., 2006a; Thompson and Singh, 2006; Dewettinck et al., 2008; Farhang et al., 2012; Farhang and Corredig, 2012).

This work will review the current understanding on the MFGM fractions, their composition, and beneficial properties. Particular focus is given to the utilization of milk phospholipids (isolated from MFGM fractions) as constituents of delivery systems, as well as the fate of encapsulated compounds during gastrointestinal transit.

\section{MILK FAT GLOBULE MEMBRANE AS A COLLOIDAL STRUCTURE}

Milk is a natural oil-in-water emulsion, with an oil phase comprising mainly fat globules with diameters of about 0.1 to $10 \mu \mathrm{m}$. These fat globules are protected from enzymatic degradation and coalescence by the MFGM, which acts as a natural emulsifier and encapsulates the nonpolar triglyceride core. The complexity of MFGM architecture ensures stable dispersion of triglycerides in the aqueous solution of milk. Polar lipids, proteins, and glycoproteins present in the membrane induce electrostatic and steric repulsion, preventing coalescence and aggregation of the fat globules (Lopez, 2011).

\section{Composition and Structure of the MFGM}

The major components of the MFGM are polar lipids with a unique and complex composition (Evers et al., 2008; Lopez, 2011). However, polar lipids are considered minor components of milk, as they comprise only 0.1 to $2 \%$ of total milk lipids (Månsson, 2008). The use of polar milk lipids as functional ingredients is gaining attention due to the increased evidence of their nutritional and health benefits upon consumption (Singh, 2006). The MFGM has been described as having a trilayer structure, with a thickness of 10 to 50 $\mathrm{nm}$ (Lopez, 2011). The surface-active inner monolayer, which surrounds the triglyceride core, is composed of polar lipids deriving from the endoplasmic reticulum. The central layer appears denser by electron microscopy and it contains mainly proteins (Mather and Keenan, 1998). Finally, the outer layer is a bilayer membrane of polar lipids. Loosely attached and transmembrane proteins, as well as cholesterol molecules, are present in the external layer (Gallier et al., 2010). Glycoproteins are also present on the surface, with carbohydrate domains oriented into solution (Lopez et al., 2010).

The most abundant polar lipids described in MFGM are glycerophospholipids, including phosphatidylcholine (PC, 35-36\% of total polar lipids), phosphatidylethanolamine (PE, 27-30\%), phosphatidylinositol (PI, 5-11\%), and sphingolipids, mainly sphingomyelin (SM, 25\%; Lopez et al., 2008). Glycerophospholipids and SM are classified as phospholipids due to the presence of a phosphate group in the polar head. Glycerol forms the backbone of glycerophospholipids, esterified with 2 fatty acids and a phosphate group with organic residues (choline, ethanolamine, or inositol, among others), whereas sphingolipids have sphingosine as backbone with a fatty acid and a phosphocholine head group. Other sources of phospholipids, such as egg or soy, differ in composition, with $\mathrm{PC}$ being the main phospholipid present in egg, and a mixture of PC, PE, and PI being described for soy (Burling and Graverholt, 2008; Farhang and Corredig, 2012).

Regarding the concentration of polar lipids in milk, a study has reported a content $28 \%$ higher in cow milk than in buffalo milk. This difference is associated with the smaller size distribution of the fat globules in cow milk and, consequently, their greater surface area compared with buffalo milk (Ménard et al., 2010). In addition, the fat globule size affects polar lipid composition: PI was found in higher concentration in fat globules with an average diameter of $2 \mu \mathrm{m}$, whereas PE concen- 
tration was higher in globules with an average diameter of $3 \mu \mathrm{m}$, and PC concentration was not affected by size (Mesilati-Stahy et al., 2011).

Although the composition of MFGM has been well studied over the last decades, its structure is still under discussion and not well understood. Some studies describe a random organization of polar lipids in the external bilayer of MFGM, which corresponds to the Singer and Nicolson (1972) fluid mosaic model of cell membranes (Michalski et al., 2005b; Dewettinck et al., 2008). However, the application of microscopy imaging techniques in the recent years has led to detailed descriptions of the lateral organization of phospholipids, highlighting the heterogeneous distribution of lipids and proteins in the MFGM (Gallier et al., 2010). Fluorescence microscopy using lipophilic probes and fluorescent conjugates of lectins to stain MFGM in harvested milk fat demonstrated the presence of various distribution patterns (Evers et al., 2008). The first results that supported the presence of lipid rafts on MFGM were published by Lopez et al. (2010), using confocal laser scanning microscopy on bovine milk samples. Those authors used an exogenous phospholipid as PE labeled with a fluorescent dye -rhodamine - that increases the polarity of the phospholipid and consequently the incorporation in MFGM and lectins to identify carbohydrate moieties. The images obtained from confocal microscopy showed unstained circular areas in the lateral organization due to the presence of liquid-ordered phases rich in sphingolipids and cholesterol in a stained liquid-disordered matrix of unsaturated glycerophospholipids. The presence of liquid-ordered domains was also demonstrated with in situ structural experiments on human milk fat globules; however, these domains differed in size and shape from bovine milk fat globule domains. This difference was attributed to differences in composition, in particular to variation in SM and cholesterol concentrations between species (Lopez and Ménard, 2011). The lateral segregation of polar lipids seems to vary in different stages of human lactation (Zou et al., 2012). Furthermore, the size of SM-cholesterol domains changes with a change in temperature from 4 to $37^{\circ} \mathrm{C}$ on mature globules (Zou et al., 2012). The rearrangement of components with temperature has also been shown in buffalo milk fat globules (Nguyen et al., 2016).

\section{Bioactivity of MFGM Extracts}

In addition to the nutritional value of MFGM, researchers have focused on health benefits associated with consumption of its main components; namely, the milk phospholipids and minor proteins present in the membrane (Rueda et al., 2008; Benyacoub et al., 2012).
Sphingolipids and their metabolites have shown antiproliferative activity on cancer cells; glycosphingolipids have been associated with immune activity or cell signaling; xanthin dehydrogenase and oxidase $(\mathrm{XDH} / \mathrm{XO})$, a protein located between the layers of polar lipids, has an antibacterial effect; and MUC1, a major glycosylated protein present in the outer bilayer, inhibits binding of enteric bacteria to the gastrointestinal epithelium (Martin et al., 2004; Parker et al., 2010). These are just a few examples of the extensive research that has been conducted on single components present in the MFGM. However, less research has been conducted on the bioactivity of MFGM extracts or fractions as a whole.

There is evidence in the literature of the anti-inflammatory effect of MFGM fractions. A recent human dietary intervention study analyzed the effect of these fractions (administered at 34\% of total energy) in a high saturated fat diet on the postprandial metabolic and inflammatory response of obese adults (Demmer et al., 2016). Individuals on an MFGM-supplemented diet had higher serum concentrations of the anti-inflammatory cytokine IL-10; reduced levels of the proinflammatory cytokines IL-6, IL- 8 , and tumor necrosis factor- $\alpha$; lower insulin response; and lower levels of total cholesterol. Similarly, MFGM isolates have been shown to decrease the systemic inflammatory response induced by LPS in mice $(10 \mathrm{mg} / \mathrm{kg}$ of LPS and $12.5 \%$ MFGM diet supplementation): animals fed with the isolates showed lower serum levels of proinflammatory cytokines than control animals (Snow et al., 2011).

Milk fat globule membrane fractions may have an immunomodulatory effect. An ex vivo study shows that these fractions isolated from raw milk suppress proliferation of splenocytes when stimulated either with LPS or concanavalin A (both polyclonal activators), as shown by the decrease of IFN- $\gamma$ and tumor necrosis factor- $\alpha$ secretion (Zanabria et al., 2014a). Recently, it was demonstrated that this immunoregulatory activity of is not limited to MFGM extracted from raw milk but is evident in fractions extracted from pasteurized cream. Figure 1 illustrates the results obtained with a proliferation assay on splenocytes (Zanabria et al., 2014a). The values were normalized to the optical density of nonactivated control cells in basal conditions. The MFGM extracts from heat-treated (pasteurized) or untreated samples reduced cell proliferation levels to close to the basal rate. In general, undigested MFGM fractions showed more activity than MFGM extracts after digestion, but in all cases there was a significant decrease compared with control cells after stimulation. The results indicated that enzymatic hydrolysis by simulated gastric and duodenal fluids, and particularly by enzymes such as trypsin and phospholipase $\mathrm{A}_{2}$, affected the bioactivity of the samples. The lower response may 


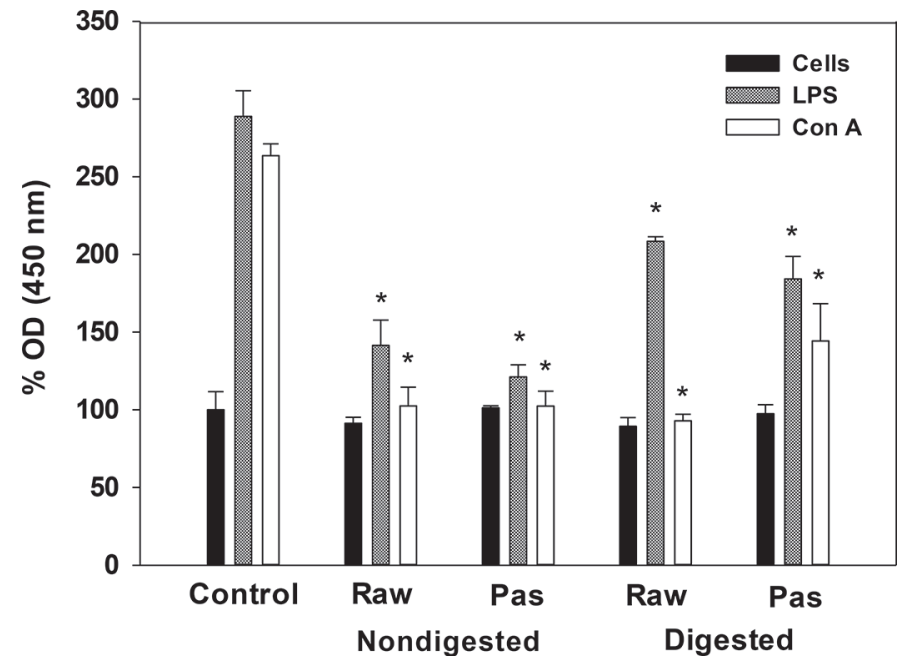

Figure 1. The effect of milk fat globule membrane (MFGM) extracted from raw and pasteurized (Pas) milk cream on the proliferation rate of splenocytes. Samples were tested before and after in vitro digestion using trypsin and phospholipase $\mathrm{A}_{2}$. Cells were incubated with concanavalin A (Con A; $2.5 \mu \mathrm{g} / \mathrm{mL})$ or LPS $(20 \mu \mathrm{g} / \mathrm{mL})$ with or without sample $(100 \mu \mathrm{g}$ of protein/mL) for $48 \mathrm{~h}$. Results (optical density, OD, at $450 \mathrm{~nm}$ ) are means $\pm \mathrm{SD}$ of 3 independent experiments. ${ }^{*} P<0.05$ : Statistical differences within each group of treatments (Cells, LPS or Con A).

be due to changes in the molecular components, protein and lipid fractions, or the supramolecular structure of the MFGM. The response of cells stimulated with MFGM isolates after digestion differed depending on the mitogen used, with bioactivity being better preserved in concanavalin A-activated cells due to T-cell population suppression (Sharma et al., 2007). More work is needed to better understand the mechanisms related to the immune modulation of the splenocytes shown in Figure 1.

In addition to studies related to immune system regulation, the anticarcinogenic potential of MFGM isolates has been the focus of much research effort. Native MFGM isolate from raw milk has shown an antiproliferative effect on HT-29 cells (a colon cancer cell line) by activation of caspase-3, a marker of programmed cell death (Zanabria et al., 2013). Similar results were found for the epithelial colorectal adenocarcinoma cell line Caco-2, supporting the antiproliferative effect of MFGM extracts; however, heat treatment of milk at $80^{\circ} \mathrm{C}$ for $10 \mathrm{~min}$ before extraction significantly reduced the bioactivity (Zanabria et al., 2014b). Processing of cream with alternative nonthermal processing methods, such as pulsed electrical field, shows great potential for the preservation of this bioactivity, as shown by the reduced proliferation of HT-29 cells (Xu et al., 2015). More evidence on the protective effect against colon cancer, in particular, is shown by the reduction of aber- rant crypt foci in rats having a diet supplemented with MFGM fractions (Snow et al., 2010).

Antimicrobial properties of MFGM fractions have been described in recent years. Whole-membrane fractions have been shown to inhibit proliferation of Salmonella Typhimurium and Pseudomonas fluorescens, with less sensitivity for Escherichia coli O157:H7 or Listeria monocytogenes (Clare et al., 2008). In addition, Guri et al. (2012) demonstrated that adherence and internalization of Salmonella Enteritidis in HT-29 cells was significantly inhibited by goat MFGM and to a greater extent than samples from bovine milk. Bovine MFGM fractions have also been shown to reduce the virulence of $E$. coli $\mathrm{O} 157: \mathrm{H} 7$ due to inhibition in gene expression of Shiga toxin (Tellez et al., 2012). In contrast to the observations of the antiproliferative effect of MFGM extracts on cancer cells, heat treatment of cream samples did not reduce preventive properties on virulence and internalization of bacteria described for membrane fractions (Guri et al., 2012; Tellez et al., 2012). Antimicrobial activity of MFGM fractions has not only been assessed in vitro; a recent study carried out in infants showed that a diet supplemented with bovine MFGM extracts (4\% wt/wt based on protein content) reduced the risk of acute otitis (Timby et al., 2015). Inhibition of Helicobacter pylori infection in mice has also been probed using $400 \mathrm{mg}$ of MFGM isolate/ $\mathrm{kg}$ of BW (Wang et al., 2001).

Recent research has focused on the potential use of MFGM isolates as antiviral food ingredients. Whole extracts isolated from buttermilk or whey cream showed anti-infective activity against rotavirus. In this case, the activity was attributed to the lipid components (Fuller et al., 2013). Source seems to affect activity, because buttermilk extracts showed greater activity than MFGM isolated from cheese whey.

\section{Milk Phospholipid Extraction}

The unique composition of the MFGM and the health and techno-functional properties of its extracts have encouraged researchers to develop various isolation methodologies. Extraction of MFGM and its components have been reported for whole milk, cream, buttermilk, and butter serum. At the laboratory scale, MFGM can be extracted by separating cream by centrifugation, followed by washing steps to remove the serum components. Subsequent freeze-thaw cycles destabilize the fat globules and the addition of sodium citrate dissociates the remaining casein micelles (Dewettinck et al., 2008; Tellez et al., 2012; Zanabria et al., 2013). Ultracentrifugation is then used to collect MFGM extracts (Tellez et al., 2012; Zanabria et al., 2013). On an industrial 
scale, buttermilk and whey buttermilk, products of butter and cheese manufacturing, are used as the main source of MFGM. Membrane filtration is often used to concentrate the MFGM. A membrane pore size $<0.15$ $\mu \mathrm{m}$ and a $\mathrm{pH}$ adjusted to 7.5 are needed for optimal polar lipid retention (Rombaut et al., 2007). The quality of the MFGM extract will depend on its processing history, and more work is needed to better understand how processing affects the structure and functionality of the MFGM.

Microfiltration of buttermilk has also been reported to be a suitable method to concentrate MFGM. The concentration factor for phospholipids can be increased using buttermilk obtained from washed cream (Morin et al., 2007). Incorporation of sodium citrate to disrupt micellar caseins decreases casein contamination from 30 to $6 \%$ of total proteins, and consequently increases the MFGM ratio in isolates (Corredig et al., 2003). Ultrafiltration in combination with hydrolysis is thought to increase the phospholipid ratio in the extracts (Konrad et al., 2013).

As for the lipid fraction of MFGM, supercritical fluid extraction and pressurized liquid extraction have emerged as means to reduce the use of organic solvents for lipid extraction. Residual triglycerides from buttermilk can be successfully removed using supercritical extraction with $\mathrm{CO}_{2}$ (Fuller et al., 2013). Supercritical fluid combined with membrane filtration has been used to obtain a concentrated polar lipids extract from buttermilk, as well as a powder extract (Astaire et al., 2003; Costa et al., 2010). Polar lipid fractions were obtained from buttermilk by pressurized liquid extraction using ethanol; such fractions could be used at functional food additives (Castro-Gómez et al., 2016).

\section{MILK PHOSPHOLIPID LIPOSOMES AS DELIVERY SYSTEMS}

The use of delivery systems in foods could provide protection and controlled release for bioactive substances during digestion. The challenges are related to a limited bioefficacy of the compounds due not only to instability during processing or storage, but also to their breakdown during gastrointestinal transit. Phospholipids vesicles - liposomes - are spherical shell bilayer structures that have been used in the pharmaceutical and cosmetic industries, and more recently in food products, as delivery systems. The versatility of liposome vesicles resides in their ability to entrap hydrophilic bioactives in the aqueous core and hydrophobic molecules within the bilayer membrane. An important aspect of liposomes is that they are biologically compatible and part of the mixed micellar system that

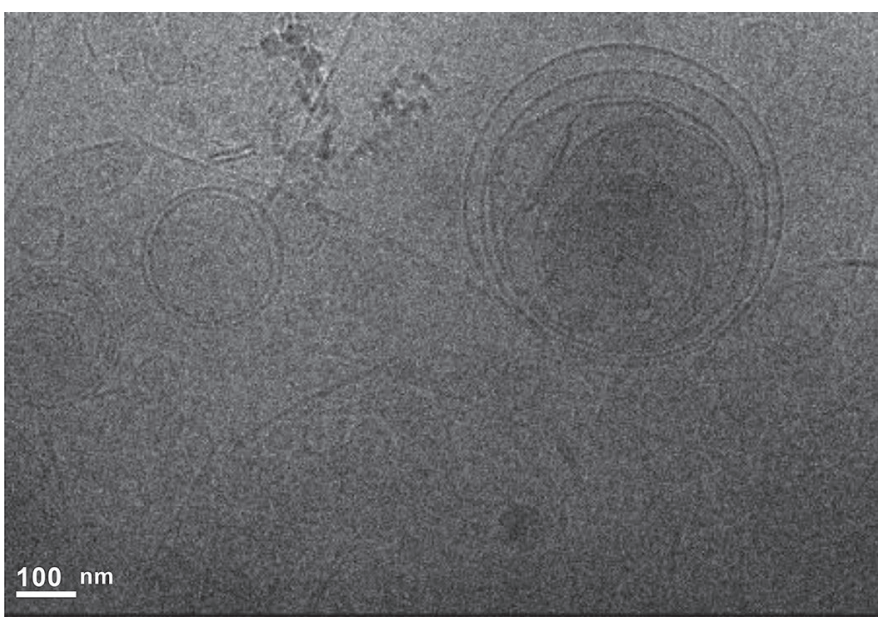

Figure 2. Cryo-transmission electron micrograph of liposomes prepared with milk phospholipids in $20 \mathrm{mM}$ imidazole- $50 \mathrm{mM} \mathrm{NaCl}$ buffer. Images were taken immediately after preparation. Samples were pipetted onto a quantifoil grid and excess was blotted off in a vitrobot (FEI, Vitrobot, Thermo Fisher Scientific, Eindhoven, the Netherlands). The specimen was transferred to a Gatan 626 Cryo holder (Warrendale, PA) and viewed in a Tecnai G2 F20 TEM microscope (Eindhoven, the Netherlands). Bar $=100 \mathrm{~nm}$. Photo courtesy of Y. Li, University of Guelph, Guelph, ON, Canada.

functions in the digestive system to deliver nutritional compounds to epithelial cells (Martins et al., 2007).

Traditionally, liposomes have been prepared using phospholipids isolated from soy or egg (Vuillemard, 1991; Mozafari et al., 2008; Maherani et al., 2011). In the last decade, phospholipids from milk have become a viable alternative (Singh, 2006). Conventional techniques for liposome preparation often use organic solvents; for food applications, microfluidization, sonication, or membrane extrusion are preferred methods (Taylor et al., 2005; Thompson and Singh, 2006). Figure 2 shows a cryogenic transmission electron microscopy (CryoTEM) image of milk unilamellar and multilamellar phospholipid vesicles obtained using microfluidization.

Liposomes prepared with milk phospholipids show lower membrane permeability, higher phase-transition temperature, and a thicker membrane compared with liposomes obtained with soy phospholipids (Thompson et al., 2006b). Moreover, milk phospholipid liposomes are more stable during storage, high processing temperatures, and changes in $\mathrm{pH}$ conditions than soy phospholipid liposomes (Thompson et al., 2006a).

\section{Encapsulation Behavior of Milk Phospholipid Liposomes}

Due to their different structures, bilayer organization, and composition, differences in the encapsulation efficiency have been found for milk phospholipid liposomes 
compared with soy phospholipid liposomes (Thompson et al., 2009).

The capacity of milk phospholipids to encapsulate hydrophilic molecules such as ascorbic acid or potassium chromate has been reported (Thompson et al., 2009; Farhang et al., 2012). For example, liposomes with an apparent diameter of $100 \mathrm{~nm}$ prepared by microfluidization entrap about $26 \%$ of the original ascorbic acid. When stored at neutral $\mathrm{pH}$ and $4^{\circ} \mathrm{C}$, such liposomes remained stable and retained $67 \%$ of ascorbic acid after 7 wk (Farhang et al., 2012). It has also been reported, using 2 model hydrophobic and hydrophilic molecules, $\beta$-carotene and potassium chromate, respectively, that milk phospholipid liposomes have a higher encapsulation efficiency than soy phospholipid liposomes (Thompson et al., 2009).

Other hydrophilic molecules, such as tea polyphenols, have been successfully encapsulated into milk phospholipid liposomes prepared using high-pressure homogenization (Gülseren and Corredig, 2013). Soy phospholipid liposomes show lower efficiency of encapsulation for tea polyphenols compared with milk phospholipid liposomes; milk phospholipid liposomes had lesser release of encapsulated molecules during storage, higher encapsulation efficiency (almost $60 \%$ with $4 \mathrm{mg} / \mathrm{mL}$ of tea polyphenol extract), and better physical stability (Gülseren and Corredig, 2013). Moreover, tea polyphenols encapsulated in milk phospholipid liposomes demonstrated high bioefficacy in reducing the proliferation of the adenocarcinoma cell line HT-29 and, although nonencapsulated polyphenols showed greater inhibition, the liposome dispersions ensured slow delivery of the bioactive (Gülseren et al., 2012).

Liposomes formulated using milk phospholipids also have potential for use as an efficient delivery system for hydrophobic bioactives. An ultrasonic dispersion method has been used to prepare liposomes entrapping curcumin, a molecule with low chemical stability, low solubility in water, and low bioavailability (Jin et al., 2016). Curcumin was incorporated in milk liposomes with an encapsulation efficiency of about $74 \%$ and an average particle diameter of $200 \mathrm{~nm}$. Liposomes ensured better release behavior of curcumin compared with unencapsulated dispersion, and showed reduced degradation of the bioactive following exposure to light or temperature. Simultaneous encapsulation of hydrophobic and hydrophilic compounds using milk phospholipids has also been reported. Incorporation of $\beta$-carotene in ascorbic acid liposomes increased particle size from 100 to $200 \mathrm{~nm}$ with an encapsulation efficiency of 92 and $26 \%$ for $\beta$-carotene and ascorbic acid, respectively (Farhang and Corredig, 2012).

Other applications of milk phospholipid liposomes have been described in the literature. For example, salmon protein hydrolysates, with demonstrated antidiabetic and antioxidant activity, were encapsulated in milk phospholipid liposomes coated with chitosan, a charged polysaccharide. The maximum encapsulation rate, $71 \%$, was reached using $10 \%$ phospholipids and $0.4 \%$ chitosan. The diffusion of hydrolysates through the bilayer during storage at $4^{\circ} \mathrm{C}$ or $20^{\circ} \mathrm{C}$ was significantly reduced by coating with chitosans ( $\mathrm{Li}$ et al., 2015). The efficacy for drug delivery with milk phospholipid vesicles has also been demonstrated using animal models (Maswadeh et al., 2015a,b).

\section{Interactions, Breakdown, and Release of Compounds During Gastrointestinal Transit}

It is crucial to understand how transit through the gastrointestinal tract will affect the functionality of encapsulated bioactives in milk phospholipid liposomes. In vitro digestion methods are often used to model the physical and chemical changes occurring in delivery systems and to better understand some aspects of these complex in vivo processes (Arranz et al., 2016). Knowing how digestive enzymes and the harsh gastrointestinal environment may affect the structure and stability of milk phospholipid liposomes is essential in order to develop functional dairy foods with enhanced nutritional value. Milk phospholipids possess a unique composition, and their physical characteristics may influence transport and release of bioactives along the gastrointestinal tract (Corredig and Dalgleish, 1998; Roesch et al., 2004).

Acidic gastric conditions can destabilize the phospholipid bilayer and alter its integrity (Grit et al., 1993). Minimal changes were found in the chemical and physical properties of milk phospholipid liposomes after incubation with simulated gastric fluids containing pepsin and with $\mathrm{pH}$ of 1.5 (Liu et al., 2012). In the same study, in spite of differences in composition and membrane structure between soy and milk phospholipid liposomes, neither soy nor milk was affected during simulated in vitro gastric digestion. Similarly, it was recently shown that during in vitro gastric digestion, milk fat globules remained stable at low $\mathrm{pH}$, even after hydrolysis of some of the MFGM proteins present at the interface by pepsin (Gallier et al., 2012).

Breakdown of MFGM, as well as phospholipids, occurs during the second stage of gastrointestinal digestion because of the change in $\mathrm{pH}$ and the presence of bile salts, pancreatic lipase, and phospholipase $\mathrm{A}_{2}$ (PLA2). In vitro studies have described in detail the interfacial changes occurring during the adsorption of bile salts to milk phospholipids, and the microstructural changes occurring in the MFGM in the early stages of digestion in the small intestine (Gallier et al., 2014). Phospholipase 
$A_{2}$ is the enzyme responsible for the hydrolysis of phospholipids in the intestine. A recent study focused on the changes occurring in milk phospholipid monolayers during hydrolysis by PLA2 at the air-water interface (Gallier et al., 2013). That study helped demonstrate the effect of the lateral organization of phospholipids in the MFGM during digestion. Hydrolysis of the monolayer started in the core of the lipid-ordered domains rich in saturated SM and then progressed to the edges. The presence of proteins in the phospholipid monolayer seemed to accelerate the rate of lipid digestion (Gallier et al., 2013). These results supported earlier hypotheses that lateral organization of polar lipids, and particularly the presence of lipid rafts on milk fat membrane, may influence the accessibility of lipases (Lopez et al., 2010). The biological functionality of MFGM extracts is affected by digestion. As shown in Figure 1, enzymatic hydrolysis with PLA2 and trypsin of fractions extracted from pasteurized and raw cream resulted in a lesser response in the immunoregulatory activity of stimulated splenocytes.

The source of phospholipids may affect the breakdown of the vesicles in the duodenal step of digestion. When comparing soy and milk liposomes by in vitro digestion, the progression of fatty acid released in the in the early (duodenal) stage was higher for soy phospholipids than for milk phospholipids. Compared with soy phospholipid liposomes, milk phospholipids seemed to retain for longer their particle diameter, surface charge, and microstructure during in vitro digestion, and it was possible to increase the extent of protection of the encapsulated bioactives by using milk phospholipid liposomes due to the slower breakdown (Liu et al., 2012).

A recent study showed that milk phospholipids liposomes could successfully encapsulate positively charged lactoferrin, with an encapsulation efficiency of about $46 \%$ (Liu et al., 2013b). Simulated gastric fluids containing pepsin $(0.032 \mathrm{mg} / \mathrm{mL})$ did not hydrolyze the entrapped protein, although the diameter of the liposomes decreased, probably due to lower osmolarity in the core $(\mathrm{pH}$ 7.4) compared with an acidic gastric medium $(\mathrm{pH}$ 1.5). The milk phospholipid bilayer impedes pepsin from penetrating into the vesicle's core. Furthermore, duodenal digestion by pancreatin, containing lipase, PLA2, and cholesterol esterase, disrupted phospholipid membrane and lactoferrin was then gradually degraded. However, even after $60 \mathrm{~min}$ of in vitro digestion, some protein remained intact due, to some extent, to the protective effect of liposomes (Liu et al., 2013b).

Controlled release and enhanced bioavailability of functional ingredients in liposomes may be further improved by preparation of milk phospholipid liposomes and polysaccharides. As previously mentioned, chitosan has been used to improve stability during in vitro digestion ( $\mathrm{Li}$ et al., 2015). The effect of polyelectrolyte coatings of polysaccharides such as chitosan and alginate is not dependent on the phospholipid source (Liu et al., 2013a).

Liposomes are biological compatible assembly structures, well known for their ability to penetrate into epithelial cells by phagocytosis (Hillaireau and Couvreur, 2009). Specific and nonspecific interactions between liposomes and the cell membrane surface occur before internalization (Düzgüneş and Nir, 1999). Because of the unique surface composition of the MFGM, milk phospholipid liposomes or vesicles prepared with MFGM extracts may serve important biological functions during digestion (Argov-Argaman et al., 2010).

Recent research has studied the bioavailability of epigallocatechin gallate (EGCG) or $\beta$-carotene encapsulated in milk phospholipids liposomes using Caco-2 monolayers, a common model to study absorption and uptake of bioactives (Li et al., 2017). Recovery of EGCG in the basolateral compartment and carotene in cell lysates was lower for liposome formulations compared with fresh solutions. It was concluded that transport of liposomes through epithelial cells occurs slowly compared with that of free molecules. However, it is important to note that when studying the uptake of nutrients, epithelial cell models are not sufficient because the role of the intestinal mucus needs to be taken into account. The mucus covers the epithelium of the gastrointestinal tract, acting as a protective barrier for pathogens and nutrients (Cone, 2009). In vitro approaches coupling human mucus-producing cells (HT29-MTX) with absorptive cells (Caco-2) are valuable methods to predict the capabilities of delivery systems as carriers of bioactives (Guri et al., 2013).

Recent work examined possible interactions between milk phospholipid liposomes and intestinal mucus using drop tensiometry ( $\mathrm{Li}$ et al., 2017). The results were completed with studies of the uptake of model bioactives using cocultures of HT29-MTX (mucus producers) and Caco-2 cells. No differences were found in surface tension between different phospholipid sources in mixed mucus-phospholipid interfaces. However, the study clearly demonstrated a difference in interactions between milk phospholipid and soy phospholipid vesicles, and this may play a role in the entrapment kinetics in the mucus layer and the modulation of absorption of the nutrients in the intestinal tract (Li et al., 2017).

\section{CONCLUSIONS AND OUTLOOK}

Research continues to demonstrate the uniqueness of the structure of MFGM, and it is clear that such isolates can be used as functional ingredients, with tech- 
nological as well as nutritional functionality. Milk fat globule membrane fractions isolated from buttermilk, the byproduct of butter manufacturing, have shown important beneficial health properties such as anticancer, immune modulatory, or anti-inflammatory activities. The effects of MFGM structure and function still need to be explored. With increasing availability of MFGM extracts, it will become imperative to understand their changes in properties as a function of processing history. As the biological functionality of MFGM becomes more evident, fine-tuning the extraction and transformation processes will become necessary when creating MFGM ingredients.

Milk phospholipids obtained from the MFGM show a unique composition and constitute about $50 \%$ of the total MFGM. Their use in building liposomal structures brings exceptional potential, especially for encapsulation of bioactives. Milk phospholipid vesicles show unique stability and encapsulation properties compared with liposomes prepared from other sources of phospholipids such as soy. Although successful encapsulation of hydrophobic and hydrophilic compounds has been reported, further research is needed to fully understand the transformations and interactions occurring during gastrointestinal transit, and the effect of these changes on absorption and uptake. Better understanding of the structure-function relationship in these colloidal structures and the fate of the bioactive molecules encapsulated will aid in the development of functional dairy foods with beneficial properties beyond nutrition.

\section{ACKNOWLEDGMENTS}

This work was partly funded by the Natural Sciences and Engineering Council of Canada, through the Canada Research Chair program and Dairy Farmers of Ontario. The first author was supported by the Alfonso Martin Escudero Foundation (Madrid, Spain), through a postdoctoral fellowship.

\section{REFERENCES}

Argov, N., S. Wachsmann-Hogiu, S. L. Freeman, T. Huser, C. B. Lebrilla, and J. B. German. 2008. Size-dependent lipid content in human milk fat globules. J. Agric. Food Chem. 56:7446-7450. https://doi.org/10.1021/jf801026a.

Argov-Argaman, N., J. T. Smilowitz, D. A. Bricarello, M. Barboza, L. Lerno, J. W. Froehlich, H. Lee, A. M. Zivkovic, D. G. Lemay, S. Freeman, C. B. Lebrilla, A. N. Parikh, and J. B. German. 2010 Lactosomes: structural and compositional classification of unique nanometer-sized protein lipid particles of human milk. J. Agric. Food Chem. 58:11234-11242. https://doi.org/10.1021/jf102495s.

Arranz, E., M. Corredig, and A. Guri. 2016. Designing food delivery systems: challenges related to the in vitro methods employed to determine the fate of bioactives in the gut. Food Funct. 7:3319 3336. https://doi.org/10.1039/c6fo00230g.
Astaire, J. C., R. Ward, J. B. German, and R. Jiménez-Flores. 2003 Concentration of polar MFGM lipids from buttermilk by microfiltration and supercritical fluid extraction. J. Dairy Sci. 86:22972307. https://doi.org/10.3168/jds.S0022-0302(03)73822-3.

Benyacoub, J., S. Blum-Sperisen, M. N. Bosco, L. J. R. Bovetto, I. Bureau-Franz, A. Donnet-Hughes, E. Schiffin, and L. Favre, inventors. 2012. Infant formula with probiotics and milk fat globule membrane components. Nestec S.A., assignee. US Pat. No. 2012/0321600A1.

Burling, H., and G. Graverholt. 2008. Milk-A new source for bioactive phospholipids for use in food formulations. Lipid Technol. 20:229-231. https://doi.org/10.1002/lite.200800058.

Castro-Gómez, P., L. M. Rodríguez-Alcalá, K. M. Monteiro, A. L. T. G. Ruiz, J. E. Carvalho, and J. Fontecha. 2016. Antiproliferative activity of buttermilk lipid fractions isolated using food grade and non-food grade solvents on human cancer cell lines. Food Chem. 212:695-702. https://doi.org/10.1016/j.foodchem.2016.06.030.

Cavaletto, M., M. G. Giuffrida, and A. Conti. 2008. Milk fat globule membrane components-A proteomic approach. Pages 129-141 in Bioactive Components of Milk. Vol. 606. Z. Bösze, ed. Springer, New York, NY.

Clare, D. A., Z. Zheng, H. M. Hassan, H. E. Swaisgood, and G. L. Catignani. 2008. Antimicrobial properties of milk fat globule membrane fractions. J. Food Prot. 71:126-133.

Cone, R. A. 2009. Barrier properties of mucus. Adv. Drug Deliv. Rev. 61:75-85. https://doi.org/10.1016/j.addr.2008.09.008.

Corredig, M., and D. G. Dalgleish. 1998. Characterization of the interface of an oil-in-water emulsion stabilized by milk fat globule membrane material. J. Dairy Res. 65:465-477.

Corredig, M., R. R. Roesch, and D. G. Dalgleish. 2003. Production of a novel ingredient from buttermilk. J. Dairy Sci. 86:2744-2750. https://doi.org/10.3168/jds.S0022-0302(03)73870-3.

Costa, M. R., X. E. Elias-Argote, R. Jiménez-Flores, and M. L. Gigante. 2010. Use of ultrafiltration and supercritical fluid extraction to obtain a whey buttermilk powder enriched in milk fat globule membrane phospholipids. Int. Dairy J. 20:598-602. https://doi. org/10.1016/j.idairyj.2010.03.006.

Demmer, E., M. D. Van Loan, N. Rivera, T. S. Rogers, E. R. Gertz, J. B. German, J. T. Smilowitz, and A. M. Zivkovic. 2016. Addition of a dairy fraction rich in milk fat globule membrane to a high-saturated fat meal reduces the postprandial insulinaemic and inflammatory response in overweight and obese adults. J. Nutr. Sci. 5:e14 https://doi.org/10.1017/jns.2015.42.

Dewettinck, K., R. Rombaut, N. Thienpont, T. T. Le, K. Messens, and J. Van Camp. 2008. Nutritional and technological aspects of milk fat globule membrane material. Int. Dairy J. 18:436-457. https:// doi.org/10.1016/j.idairyj.2007.10.014.

Düzgüneş, N., and S. Nir. 1999. Mechanisms and kinetics of liposome-cell interactions. Adv. Drug Deliv. Rev. 40:3-18. https://doi. org/10.1016/S0169-409X(99)00037-X.

Evers, J. M., R. G. Haverkamp, S. E. Holroyd, G. B. Jameson, D. D. S. Mackenzie, and O. J. McCarthy. 2008. Heterogeneity of milk fat globule membrane structure and composition as observed using fluorescence microscopy techniques. Int. Dairy J. 18:1081-1089. https://doi.org/10.1016/j.idairyj.2008.06.001.

Farhang, B., and M. Corredig. 2012. Milk phospholipids: A nanocarrier system for delivery of bioactive compounds. Pages 53-68 in Lipids in Nanotechnology. M. U. Ahmad, ed. Elsevier, Amsterdam, the Netherlands.

Farhang, B., Y. Kakuda, and M. Corredig. 2012. Encapsulation of ascorbic acid in liposomes prepared with milk fat globule membrane-derived phospholipids. Dairy Sci. Technol. 92:353-366. https://doi.org/10.1007/s13594-012-0072-7.

Fuller, K. L., T. B. Kuhlenschmidt, M. S. Kuhlenschmidt, R. JiménezFlores, and S. M. Donovan. 2013. Milk fat globule membrane isolated from buttermilk or whey cream and their lipid components inhibit infectivity of rotavirus in vitro. J. Dairy Sci. 96:3488-3497. https://doi.org/10.3168/jds.2012-6122.

Gallier, S., D. Gragson, R. Jiménez-Flores, and D. Everett. 2010. Using confocal laser scanning microscopy to probe the milk fat 
globule membrane and associated proteins. J. Agric. Food Chem. 58:4250-4257. https://doi.org/10.1021/jf9032409.

Gallier, S., E. Shaw, J. Cuthbert, D. Gragson, H. Singh, and R. Jiménez-Flores. 2013. Hydrolysis of milk phospholipid and phospholipid-protein monolayers by pancreatic phospholipase A2. Food Res. Int. 54:718-725. https://doi.org/10.1016/j.foodres.2013.08.019.

Gallier, S., E. Shaw, A. Laubscher, D. Gragson, H. Singh, and R. Jiménez-Flores. 2014. Adsorption of bile salts to milk phospholipid and phospholipid-protein monolayers. J. Agric. Food Chem. 62:1363-1372. https://doi.org/10.1021/jf404448d.

Gallier, S., A. Ye, and H. Singh. 2012. Structural changes of bovine milk fat globules during in vitro digestion. J. Dairy Sci. 95:35793592. https://doi.org/10.3168/jds.2011-5223.

Grit, M., W. J. M. Underberg, and D. J. A. Crommelin. 1993. Hydrolysis of saturated soybean phosphatidylcholine in aqueous liposome dispersions. J. Pharm. Sci. 82:362-366.

Gülseren, İ., and M. Corredig. 2013. Storage stability and physical characteristics of tea-polyphenol-bearing nanoliposomes prepared with milk fat globule membrane phospholipids. J. Agric. Food Chem. 61:3242-3251. https://doi.org/10.1021/jf3045439.

Gülseren, İ., A. Guri, and M. Corredig. 2012. Encapsulation of tea polyphenols in nanoliposomes prepared with milk phospholipids and their effect on the viability of HT-29 human carcinoma cells. Food Dig. 3:36-45. https://doi.org/10.1007/s13228-012-0019-8.

Guri, A., M. Griffiths, C. M. Khursigara, and M. Corredig. 2012. The effect of milk fat globules on adherence and internalization of Salmonella Enteritidis to HT-29 cells. J. Dairy Sci. 95:6937-6945. https://doi.org/10.3168/jds.2012-5734.

Guri, A., I. Gülseren, and M. Corredig. 2013. Utilization of solid lipid nanoparticles for enhanced delivery of curcumin in cocultures of HT29-MTX and Caco-2 cells. Food Funct. 4:1410-1419. https:// doi.org/10.1039/c3fo60180c.

Hillaireau, H., and P. Couvreur. 2009. Nanocarriers' entry into the cell: Relevance to drug delivery. Cell. Mol. Life Sci. 66:2873-2896. https://doi.org/10.1007/s00018-009-0053-z.

Jensen, R. G. 2002. The composition of bovine milk lipids: January 1995 to December 2000. J. Dairy Sci. 85:295-350. https://doi. org/10.3168/jds.S0022-0302(02)74079-4.

Jin, H.-H., Q. Lu, and J.-G. Jiang. 2016. Curcumin liposomes prepared with milk fat globule membrane phospholipids and soybean lecithin. J. Dairy Sci. 99:1780-1790. https://doi.org/10.3168/ jds.2015-10391.

Konrad, G., T. Kleinschmidt, and C. Lorenz. 2013. Ultrafiltration of whey buttermilk to obtain a phospholipid concentrate. Int. Dairy J. 30:39-44. https://doi.org/10.1016/j.idairyj.2012.11.007.

Li, Y., E. Arranz, A. Guri, and M. Corredig. 2017. Mucus interactions with liposomes encapsulating bioactives: Interfacial tensiometry and cellular uptake on Caco-2 and cocultures of Caco2/HT29-MTX. J. Agric. Food Chem. 92:128-137. http://dx.doi. org/10.1016/j.foodres.2016.12.010.

Li, Z., A. T. Paulson, and T. A. Gill. 2015. Encapsulation of bioactive salmon protein hydrolysates with chitosan-coated liposomes. J. Funct. Foods 19:733-743. https://doi.org/10.1016/j. jff.2015.09.058.

Liu, W., J. Liu, W. Liu, T. Li, and C. Liu. 2013a. Improved physical and in vitro digestion stability of a polyelectrolyte delivery system based on layer-by-layer self-assembly alginate-chitosan-coated nanoliposomes. J. Agric. Food Chem. 61:4133-4144. https://doi. org/10.1021/jf305329n.

Liu, W., A. Ye, C. Liu, W. Liu, and H. Singh. 2012. Structure and integrity of liposomes prepared from milk- or soybean-derived phospholipids during in vitro digestion. Food Res. Int. 48:499-506. https://doi.org/10.1016/j.foodres.2012.04.017.

Liu, W., A. Ye, W. Liu, C. Liu, and H. Singh. 2013b. Stability during in vitro digestion of lactoferrin-loaded liposomes prepared from milk fat globule membrane-derived phospholipids. J. Dairy Sci. 96:2061-2070. https://doi.org/10.3168/jds.2012-6072.

Lopez, C. 2011. Milk fat globules enveloped by their biological membrane: Unique colloidal assemblies with a specific composition and structure. Curr. Opin. Colloid Interface Sci. 16:391-404. https:// doi.org/10.1016/j.cocis.2011.05.007.
Lopez, C., V. Briard-Bion, O. Menard, F. Rousseau, P. Pradel, and J.-M. Besle. 2008. Phospholipid, sphingolipid, and fatty acid compositions of the milk fat globule membrane are modified by diet. J. Agric. Food Chem. 56:5226-5236. https://doi.org/10.1021/ jf7036104

Lopez, C., M.-N. Madec, and R. Jimenez-Flores. 2010. Lipid rafts in the bovine milk fat globule membrane revealed by the lateral segregation of phospholipids and heterogeneous distribution of glycoproteins. Food Chem. 120:22-33. https://doi.org/10.1016/j. foodchem.2009.09.065.

Lopez, C., and O. Ménard. 2011. Human milk fat globules: Polar lipid composition and in situ structural investigations revealing the heterogeneous distribution of proteins and the lateral segregation of sphingomyelin in the biological membrane. Colloids Surf. B Biointerfaces 83:29-41. https://doi.org/10.1016/j.colsurfb.2010.10.039.

Maherani, B., E. Arab-Tehrany, M. R. Mozafari, C. Gaiani, and M. Linder. 2011. Liposomes: A review of manufacturing techniques and targeting strategies. Curr. Nanosci. 7:436-452. https://doi. org/10.2174/157341311795542453.

Månsson, H. L. 2008. Fatty acids in bovine milk fat. Food Nutr. Res. 52. https://doi.org/10.3402/fnr.v52i0.1821.

Martin, H. M., J. T. Hancock, V. Salisbury, and R. Harrison. 2004. Role of xanthine oxidoreductase as an antimicrobial agent. Infect. Immun. 72:4933-4939. https://doi.org/10.1128/IAI.72.9.49334939.2004

Martins, S., B. Sarmento, D. C. Ferreira, and E. B. Souto. 2007. Lipidbased colloidal carriers for peptide and protein delivery-Liposomes versus lipid nanoparticles. Int. J. Nanomedicine 2:595-607.

Maswadeh, H. M., A. N. Aljarbou, M. S. Alorainy, M. S. Alsharidah, and M. A. Khan. 2015a. Etoposide incorporated into camel milk phospholipids liposomes shows increased activity against fibrosarcoma in a mouse model. BioMed Res. Int. https://doi. org $/ 10.1155 / 2015 / 743051$.

Maswadeh, H. M., A. N. Aljarbou, M. S. Alorainy, A. H. Rahmani, and M. A. Khan. 2015b. Coadministration of doxorubicin and etoposide loaded in camel milk phospholipids liposomes showed increased antitumor activity in a murine model. Int. J. Nanomedicine 10:2847-2855. https://doi.org/10.2147/IJN.S80820.

Mather, I. H., and T. W. Keenan. 1998. Origin and secretion of milk lipids. J. Mammary Gland Biol. Neoplasia 3:259-273.

Ménard, O., S. Ahmad, F. Rousseau, V. Briard-Bion, F. Gaucheron, and C. Lopez. 2010. Buffalo vs. cow milk fat globules: Size distribution, zeta-potential, compositions in total fatty acids and in polar lipids from the milk fat globule membrane. Food Chem. 120:544-551. https://doi.org/10.1016/j.foodchem.2009.10.053.

Mesilati-Stahy, R., K. Mida, and N. Argov-Argaman. 2011. Size-dependent lipid content of bovine milk fat globule and membrane phospholipids. J. Agric. Food Chem. 59:7427-7435. https://doi. org/10.1021/jf201373j.

Michalski, M. C., V. Briard, and P. Juaneda. 2005a. CLA profile in native fat globules of different sizes selected from raw milk. Int. Dairy J. 15:1089-1094. https://doi.org/10.1016/j.idairyj.2004.11.011.

Michalski, M. C., V. Briard, F. Michel, F. Tasson, and P. Poulain. 2005b. Size distribution of fat globules in human colostrum, breast milk, and infant formula. J. Dairy Sci. 88:1927-1940. https://doi. org/10.3168/jds.S0022-0302(05)72868-X.

Morin, P., M. Britten, R. Jiménez-Flores, and Y. Pouliot. 2007. Microfiltration of buttermilk and washed cream buttermilk for concentration of milk fat globule membrane components. J. Dairy Sci. 90:2132-2140. https://doi.org/10.3168/jds.2006-832.

Mozafari, M. R., K. Khosravi-Darani, G. G. Borazan, J. Cui, A. Pardakhty, and S. Yurdugul. 2008. Encapsulation of food ingredients using nanoliposome technology. Int. J. Food Prop. 11:833-844. https://doi.org/10.1080/10942910701648115.

Nguyen, H. T. H., M. N. Madec, L. Ong, S. E. Kentish, S. L. Gras, and C. Lopez. 2016. The dynamics of the biological membrane surrounding the buffalo milk fat globule investigated as a function of temperature. Food Chem. 204:343-351. https://doi.org/10.1016/j. foodchem.2016.02.141

Parker, P., L. Sando, R. Pearson, K. Kongsuwan, R. L. Tellam, and S. Smith. 2010. Bovine Muc1 inhibits binding of enteric bacteria 
to Caco-2 cells. Glycoconj. J. 27:89-97. https://doi.org/10.1007/ s10719-009-9269-2.

Roesch, R. R., A. Rincon, and M. Corredig. 2004. Emulsifying properties of fractions prepared from commercial buttermilk by microfiltration. J. Dairy Sci. 87:4080-4087. https://doi.org/10.3168/jds. S0022-0302(04)73550-X.

Rombaut, R., V. Dejonckheere, and K. Dewettinck. 2007. Filtration of milk fat globule membrane fragments from acid buttermilk cheese whey. J. Dairy Sci. 90:1662-1673. https://doi.org/10.3168/ jds.2006-587.

Rueda, R., A. Barranco, M. Ramirez, E. Vazquez, E. Valverde, P. Prieto, and M. H. Dohnalek. 2008. Infant formulas for early brain development. Ross Products division of Abbott Laboratories, assignee. US Pat. No. 2008/0003330A1.

Sharma, S., K. Chopra, S. K. Kulkarni, and J. N. Agrewala. 2007. Resveratrol and curcumin suppress immune response through CD28/ CTLA-4 and CD80 co-stimulatory pathway. Clin. Exp. Immunol. 147:155-163. https://doi.org/10.1111/j.1365-2249.2006.03257.x.

Singer, S. J., and G. L. Nicolson. 1972. The fluid mosaic model of the structure of cell membranes. Science 175:720-731.

Singh, H. 2006. The milk fat globule membrane-A biophysical system for food applications. Curr. Opin. Colloid Interface Sci. 11:154163. https://doi.org/10.1016/j.cocis.2005.11.002.

Snow, D. R., R. Jimenez-Flores, R. E. Ward, J. Cambell, M. J. Young, I. Nemere, and K. J. Hintze. 2010. Dietary milk fat globule membrane reduces the incidence of aberrant crypt foci in Fischer-344 rats. J. Agric. Food Chem. 58:2157-2163. https://doi.org/10.1021/ jf903617q.

Snow, D. R., R. E. Ward, A. Olsen, R. Jimenez-Flores, and K. J. Hintze. 2011. Membrane-rich milk fat diet provides protection against gastrointestinal leakiness in mice treated with lipopolysaccharide. J. Dairy Sci. 94:2201-2212. https://doi.org/10.3168/jds.2010-3886.

Taylor, T. M., J. Weiss, P. M. Davidson, and B. D. Bruce. 2005. Liposomal nanocapsules in food science and agriculture. Crit. Rev. Food Sci. Nutr. 45:587-605. https://doi.org/10.1080/10408390591001135.

Tellez, A., M. Corredig, A. Guri, R. Zanabria, M. W. Griffiths, and V. Delcenserie. 2012. Bovine milk fat globule membrane affects virulence expression in Escherichia coli O157:H7. J. Dairy Sci. 95:6313-6319. https://doi.org/10.3168/jds.2012-5560.

Thompson, A. K., A. Couchoud, and H. Singh. 2009. Comparison of hydrophobic and hydrophilic encapsulation using liposomes prepared from milk fat globule-derived phospholipids and soya phospholipids. Dairy Sci. Technol. 89:99-113. https://doi.org/10.1051/ dst/2008036

Thompson, A. K., D. Haisman, and H. Singh. 2006a. Physical stability of liposomes prepared from milk fat globule membrane and soya phospholipids. J. Agric. Food Chem. 54:6390-6397. https://doi. org $/ 10.1021 /$ jf0605695
Thompson, A. K., J. P. Hindmarsh, D. Haisman, T. Rades, and H. Singh. 2006b. Comparison of the structure and properties of liposomes prepared from milk fat globule membrane and soy phospholipids. J. Agric. Food Chem. 54:3704-3711. https://doi. org/10.1021/jf052859b.

Thompson, A. K., and H. Singh. 2006. Preparation of liposomes from milk fat globule membrane phospholipids using a microfluidizer. J. Dairy Sci. 89:410-419. https://doi.org/10.3168/jds.S00220302(06)72105-1.

Timby, N., O. Hernell, O. Vaarala, M. Melin, B. Lönnerdal, and M. Domellöf. 2015. Infections in infants fed formula supplemented with bovine milk fat globule membranes. J. Pediatr. Gastroenterol. Nutr. 60:384-389. https://doi.org/10.1097/MPG.0000000000000624.

Vanderghem, C., P. Bodson, S. Danthine, M. Paquot, C. Deroanne, and C. Blecker. 2010. Milk fat globule membrane and buttermilks: from composition to valorization. Biotechnol. Agron. Soc. Environ. $14: 485-500$

Vuillemard, J.-C. 1991. Recent advances in the large-scale production of lipid vesicles for use in food products: Microfluidization. J. Microencapsul. 8:547-562. https://doi.org/10.3109/02652049109021878.

Wang, X., S. Hirmo, R. Willén, and T. Wadström. 2001. Inhibition of Helicobacter pylori infection by bovine milk glycoconjugates in a BAlb/cA mouse model. J. Med. Microbiol. 50:430-435. https:// doi.org/10.1099/0022-1317-50-5-430.

Xu, S., M. Walkling-Ribeiro, M. W. Griffiths, and M. Corredig. 2015. Pulsed electric field processing preserves the antiproliferative activity of the milk fat globule membrane on colon carcinoma cells. J. Dairy Sci. 98:2867-2874. https://doi.org/10.3168/jds.2014-8839.

Zanabria, R. A. M. Tellez, M. Griffiths, and M. Corredig. 2013. Milk fat globule membrane isolate induces apoptosis in HT-29 human colon cancer cells. Food Funct. 4:222-230. https://doi. org/10.1039/c2fo30189j.

Zanabria, R., A. M. Tellez, M. Griffiths, S. Sharif, and M. Corredig. 2014a. Modulation of immune function by milk fat globule membrane isolates. J. Dairy Sci. 97:2017-2026. https://doi org $/ 10.3168 /$ jds.2013-7563.

Zanabria, R., A. M. Tellez, M. W. Griffiths, and M. Corredig. 2014b. The antiproliferative properties of the milk fat globule membrane are affected by extensive heating. Dairy Sci. Technol. 94:439-453. https://doi.org/10.1007/s13594-014-0171-8.

Zou, X. Q., Z. Guo, J. H. Huang, Q. Z. Jin, L. Z. Cheong, X. G. Wang, and X. B. Xu. 2012. Human milk fat globules from different stages of lactation: A lipid composition analysis and microstructure characterization. J. Agric. Food Chem. 60:7158-7167. https://doi org/10.1021/jf3013597. 